perature in any case. Those who were previously unable to feed the baby naturally have been enabled to do so. There has not been the slightest evidence of rickets in any of the babies or of osteomalacia in a mother. The dosage of vitamin $\mathrm{D}$ has not been considered, but has evidently been sufficient. My investigations have been very incomplete as my cases are few, and $x$ rays are not available to study the bone changes, as Dr. Rollier has studied them at Leysin in his clinics for heliotherapy. The cost of this treatment, excepting for the time spent in administering the light, is negligible, and the cases are under the closest observation from an early date in pregnancy.

\section{Psychology and Religion}

Dr. Richard Kay (Hartland, N. Devon) writes: In his exccedingly interesting address on psychology and religion, reported in the Journal of November 24th (p. 958), Dr. David Forsyth says " the reason for the almost universal belief in immortality needed accounting. for." May I suggest that it is d:se to the rationalization by primitive man of the instinctive avoidance of danger, common to most slow-breeding animals, into the fear of pain and death. To fear death is to wish to live for ever, which is contrary to experience. But the idea has been born, and the instinct, still active, gives us a strong bias in favour of any argument or experience which suggests that death is not the end of the individual.

\section{Prevention of "Steaming" Glass}

Dr. F, A. E. Silcock (Leicester) writes: With reference to the letter on prevention of " steaming" glass, by Dr. J. Roland Murdoch, in your issue of November 24th (p. 976), I desire to state that for very many years now I have used a method that is at once simple, inexpensive, and readily obtainable anywhere for my eyeglasses, surgical mirrors, and so forth. Rub some moist soap over the glass surface and polish it off with a piece of rag again. Ordinary hard household or toilet soap, when it is "tacky" -for example, after one has recently washed one's hands with it-will do. The effect lasts for several hours. I thin' the soap acts by lowering the surface tension. Other substances will do the same, but soap has obvious advantages.

Dr. J. Percival Brown (Bacup) writes: A very old tip used by me for all mirrors, glasses, etc., is to rub on a bit of ordinary hard, dry soap and then polish off. Any mirror is thus also easily prepared for a patient to get close to it to remove blackheads in acne cases. It is useful in a bathroom to prevent steaming of a mirror, etc.

\section{Inquiry into Contraception}

The Acting Secretary of the National Birth Control Association, of which Lord Horder is president, writes: This association has appointed a medical subcommittee consisting of practitioners actively engaged in the teaching of contraception. The object of this committee is to collect, coordinate, and from time to time draw up for publication authoritative information on all aspects of contraception for the use of the medical profession. The committee is in consultation with research workers, manufacturers, birth control clinics (both voluntary and under the public health authorities), and doctors engaged in teaching contraceptive methods throughout the country. Although much valuable experience exists, the results of which are at the disposal of the N.B.C.A., the whole subject is still at the research and experimental stage, and it is necessary to be constantly reviewing and reassessing the methods in current use. This committee would therefore be glad to hear from any doctor, clinic, or manufacturer interested in birth control, in order that it may have the fullest sources of information possible. All communications should be addressed to the secretary, National Birth Control Association, 26, Eccleston Street, S.W.1.

\section{Motor Backache and Neuralgia}

Dr. TOM A. Williams (Bordighera) writes: Pain in the back from motoring is surely due to prolonged stretching of extensor ligaments and muscular attachments, aggravated by the sudden further drag when the body is jolted backwards, forwards, or sideways by bumpings of the car. There are two factors at work. The "close-ribbed " person sags less; hence ligamental and muscular attachments are scarcely stretched. Further, he fits better the usual seat The long-backed person is farther stretched, and rarely is fitted, especially in a small car. My own remedy is to place a cushion in the small of the back about one foot square and three inches thick, firm enough to support the shoulders and maintain the lumbo-dorsal extensor curve into which it fits, and soft enough to accommodate itself to the space made by the misshape of the back of the seat. In my case this has prevented ache and strain in many a thousand-mile trip over rough roads during the past twenty years. The same device used in bed cures many a back pain reputed to be " neurasthenic" or " imaginary " or "psychological "-so often lightly dismissed by the loosely thinking. Just so, motor backache can be cured only by rest and massage, but can be prevented, even when the seat is ill constructed, by a cushion properly made.

\section{Varicella and Herpes}

Dr. D. Justin Davies (Leicester) writes: The close relation between the virus of varicella and herpes zoster is now an accepted fact. An address-I believe by Dr. James Collier -was published some years ago in the British Medical Journal, concerning the possible connexion between the viruses of acute infections of the central nervous system and those of varicella and herpes. The following cases are therefore, I think, of some interest. A girl, 10 years of age, suffered five years ago from acute anterior poliomyelitis. The result of this illness seems to be confined to the left lower limb, which is now much smaller and shorter than its fellow. She recently developed varicella. A profuse eruption appeared on the trunk and scalp with numerous spots on the face and limbs (with the exception of the affected limb, which was completely free of spots). Some time ago I attended a boy suffering from encephalitis lethargica, whose mother and father both subsequently developed herpes zoster.

\section{Medical Register: Office Edition}

The Registrar of the General Medical Council writes: Any orders for the Office Edition of the Medical Register, 1935, published by the Council at the special price of 10s. a copy, post free, must be received, with a remittance, at the office of the Council, 44, Hallam Street, Portland Place, WV 1, not later than December 31st, 1934. The Office Edition differs from the ordinary edition of the Register to the extent that it does not contain reprints of the Medical and Dentists Acts and other preliminary matter, and is printed on more inexpensive paper and bound in boards. It includes, however, the same entries relating to registered medical practitioners as are included in the ordinary edition, and is therefore equally serviceable to public authorities and others who find it necessary to ascertain whether particular persons are registered medical practitioners or not. I take the opportunity of stating that the Council also prepares monthly lists of names added to, and removed from the Register, and that particulars of the terms and conditions upon which copies of these lists may be made available can be obtained on application to the office of the Council

\section{Corrigenda}

Dr. E. Harvey (Dublin) wishes to make a correction in the report of the meeting of the Royal Academy of Medicine in Ireland on November 2nd, which was supplied to us for publication by the secretary (Journal, November 17th, p. 919). Dr. Harvey writes: "Monkeys and pigeons were the experimental animals used by Sir R. McCarrisonnot rabbits, as I am made to say. It was in the monkeys, put on a diet of autoclaved rice and fresh butter, that conditions were produced which bear a close correspondence to those found in coeliac disease (or Gee's disease)."

Another apology is due to the shade of Horace. The quotation amended last week (p. 976) should read ". . . amarı lento temperet risu."

An exhibition of microscopes, conducted by Messrs. W. Watson and Sons, Ltd., will be held in the Conference Hall of the Central Hall, Westminster, S.W., from December 10th to 15th inclusive, and will be open from 2.30 p.m. each day.

\section{Vacancies}

Notifications of offices vacant in universities, medical colleges, and of vacant resident and other appointments at hospitals, will be found at pages $54,55,56,57,60$, and 61 of our advertisement columns, and advertisements as to partnerships, assistantships, and locumtenencies at pages 58 and 59.

A short summary of vacant posts notified in the advertisement columns appears in the Supplement at page 280. 